\title{
Permanent draft genome sequence of Comamonas testosteroni KF-1
}

\author{
Michael Weiss, ${ }^{1,2}$, Anna I. Kesberg ${ }^{1}$, Kurt M. LaButti ${ }^{3}$, Sam Pitluck ${ }^{3}$, David Bruce ${ }^{4}$, Loren \\ Hauser $^{5}$, Alex Copeland ${ }^{3}$, Tanja Woyke ${ }^{3}$, Stephen Lowry ${ }^{3}$, Susan Lucas ${ }^{3}$, Miriam Land ${ }^{5}$, \\ Lynne Goodwin ${ }^{3,4}$, Staffan Kjelleberg ${ }^{6}$, Alasdair M. Cook ${ }^{1,2}$, Matthias Buhmann', Torsten \\ Thomas $^{6}$, and David Schleheck ${ }^{1,2^{*}}$ \\ ${ }^{1}$ Department of Biological Sciences, University of Konstanz, Germany \\ ${ }^{2}$ Konstanz Research School Chemical Biology, University of Konstanz, Germany \\ ${ }^{3}$ DOE Joint Genome Institute, Walnut Creek, California, USA \\ ${ }^{4}$ Los Alamos National Laboratory, Bioscience Division, Los Alamos, New Mexico, USA \\ ${ }^{5}$ Oak Ridge National Laboratory, Oak Ridge, Tennessee, USA \\ ${ }^{6}$ Centre for Marine Bio-Innovation and School of Biotechnology and Biomolecular Science, \\ University of New South Wales, Sydney, Australia
}

*Corresponding author: David Schleheck (david.schleheck@uni-konstanz.de)

Keywords: Comamonas testosteroni KF-1, aerobic, Gram-negative, Comamonadaceae, xenobiotic surfactant biodegradation

Comamonas testosteroni KF-1 is a model organism for the elucidation of the novel biochemical degradation pathways for xenobiotic 4-sulfophenylcarboxylates (SPC) formed during biodegradation of synthetic 4-sulfophenylalkane surfactants (linear alkylbenzenesulfonates, LAS) by bacterial communities. Here we describe the features of this organism, together with the complete genome sequence and annotation. The 6,026,527 bp long chromosome (one sequencing gap) exhibits an average $\mathrm{G}+\mathrm{C}$ content of $61.79 \%$ and is predicted to encode 5,492 protein-coding genes and 114 RNA genes.

\section{Introduction}

Comamonas testosteroni strain KF-1 (DSM14576) was isolated for its ability to degrade xenobiotic sulfophenylcarboxylates (SPC), which are degradation intermediates of the synthetic laundry surfactants linear alkylbenzenesulfonates (LAS) [1]. LAS is in use worldwide (appr. $3 \times 10^{6}$ tons per year [2]) and consists of a complex mixture of linear alkanes $\left(\mathrm{C}_{10}-\mathrm{C}_{13}\right)$ sub-terminally substituted by 4sulfophenyl rings (i.e., 38 different compounds) [2]. Commercial LAS is completely biodegradable, as known for more than 50 years [3], e.g., in sewage treatment plants, and its degradation is catalyzed by heterotrophic aerobic bacterial communities in two steps. First, an initial degradation step is catalyzed by bacteria such as Parvibaculum lavamentivorans DS-1 ${ }^{\mathrm{T}}$ [4] through activation and shortening of the alkyl-chains of LAS, and many short-chain degradation intermediates are excreted by these organisms, i.e., approximately 50 different SPCs and related compounds [1,5-8]. Secondly, the ultimate degradation step, i.e., mineralization of all SPCs, is catalyzed by other bacteria in the community, and one representative of these is Comamonas testosteroni $\mathrm{KF}-1$. In particular, strain KF-1 was isolated from a laboratory trickling filter that had been used to enrich a bacterial community from sewage sludge that completely degraded commercial LAS and SPCs $[1,6]$. Strain KF-1 is able to utilize four individual SPCs (both enantiomers), namely $R / S-3$ -

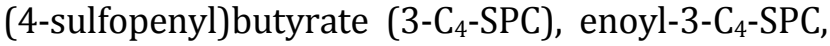
$R / S$-3-(4-sulfopenyl)pentanoate $\left(3-\mathrm{C}_{5}-\mathrm{SPC}\right)$, and enoyl-3- $\mathrm{C}_{5}$-SPC (see therefore also below), as novel carbon an energy sources for its heterotrophic aerobic growth $[1,9,10]$.

The first Comamonas testosteroni (formerly Pseudomonas testosteroni [11]) strain, type-strain ATCC 11996, was enriched from soil and isolated in 1952 for its ability to degrade testosterone $[12,13]$. Since then, the physiology, biochemistry, genetics, and regulation of steroid degradation in this and in other $C$. testosteroni strains have been elucidated in great detail [e.g., 14-21]. Most recently, the genome of $C$. testosteroni ATCC $11996^{\mathrm{T}}$ has been sequenced in order to further improve the understanding of the molecular basis for the degradation of steroids [22]. 
In the environment, members of the genus Comamonas may also be important degraders of aromatic compounds other than steroids, especially of xenobiotic pollutants, since they have frequently been enriched and isolated for their ability to utilize (xenobiotic) aromatic compounds. For example, Comamonas sp. strain JS46 is able to grow with 3-nitrobenzoate [23], Comamonas sp. strain CNB-1 with 4-chloronitrobenzene [24], C. testosteroni T-2 with 4-toluenesulfonate and 4-sulfobenzoate [25], C. testosteroni WDL7 with chloroaniline [26], Comamonas sp. strain JS765 with nitrobenzene [27], Comamonas sp. strain B-9 with lignin-polymer fragments [28], C. testosteroni B-356 with biphenyl and 4-chlorobiphenyl [29], Comamonas sp. strain KD-7 with dibenzofuran [30], Comamonas sp. strain 4BC with naphthalene-2-sulfonate [31], or $C$. testosteroni SPB-2 (as well as strain KF-1) with 4-sulfophenylcarboxylates [1]. In several $C$. testosteroni strains, the physiology, biochemistry, genetics, and/or regulation of the utilization of aromatic compounds have been elucidated [e.g., $10,23,25,27,29,32-48]$. Furthermore, the genome sequence of (plasmid-cured) C. testosteroni CNB-2 has been published [24], and the sequence of its plasmid pCNB1 (of C. testosteroni CNB-1) [49], in order to further improve the understanding of the molecular basis for the ability of $C$. testosteroni to degrade such a large array of aromatic compounds.

Members of the genus Comamonas are able to cope with harsh environmental conditions such as high concentrations of arsenate [50,51], zinc [52], cobalt and nickel [53], or phenol [54], and can exhibit increased resistance to oxidative stress [55] or antibiotics [56]. Another C. testosteroni genome sequence, of strain S44, has recently been established in order to improve the understanding of the molecular basis for its resistance to increased concentrations of zinc [52]. Notably, an increased antibiotic resistance (and enhanced insecticide catabolism) as a consequence of induction of the steroid degradation pathway has been shown for $C$. testosteroni ATCC 11996' [56].

Here, we present a summary classification and a set of features for another $C$. testosteroni strain, strain $\mathrm{KF}-1$, which has been genome-sequenced in order to improve the understanding of the molecular basis for its ability to degrade xenobiotic compounds, particularly xenobiotic, chiral $3-\mathrm{C}_{4}-\mathrm{SPC}$, and how this novel degradation pathway has been assembled in this organism, together with the description of its draft genome sequence and annotation. The genome sequence and its annotation have been established as part of the Microbial Genomics Program 2006 of the DOE Joint Genome Institute, and are accessible via the IMG platform [57].

\section{Classifications and features Morphology and growth conditions}

C. testosteroni $\mathrm{KF}-1$ is a rod-shaped (size, appr. 0.5 x $2 \mu \mathrm{m}$, Figure 1) Gram-negative bacterium that can be motile and grows strictly aerobically with complex medium (e.g., in LB- or peptone medium) or in a prototrophic manner when cultivated in mineral-salts medium [58] with a single carbon source (e.g., acetate). Strain KF-1 grows overnight on LB-agar plates and forms whitish-beige colonies [Table 1]. The strain grew with all amino acids tested (D-alanine, L-alanine, L-aspartate, Lphenylalanine, L-valine, glycine, L-histidine, Lmethionine), but not with any of the sugars tested (D-glucose, D-fructose, D-galactose, D-arabinose, and D-maltose). Strain KF-1 utilized the following alcohols and carboxylic acids when tested (in this study): ethanol, acetate, glycerol, glycolate, glyoxylate, butanol, butyrate, isobutyrate, succinate, meso-tartaric acid, D- and L-malate, mesaconate, and nicotinate. Furthermore, strain KF-1 was positive for growth with poly-betahydroxybutyrate (this study). Strain KF-1 is able to utilize the steroids testosterone and progesterone (confirmed in this study), as well as taurocholate and cholate (and taurine and $\mathrm{N}$ methyl taurine) [19], and taurodeoxycholate; strain KF-1 was tested negative for growth with cholesterol, ergosterol, 17 $\beta$-estradiol and ethinylestradiol (this study), correlating with the findings for C. testosteroni strain TA441 [20].

In respect to other aromatic compounds, strain KF-1 is known to utilize benzoate, 3- and 4hydroxybenzoate, protocatechuate $\quad(3,4-$ dihydroxybenzoate), gentisate (2,5dihydroxybenzoate), phthalate, terephthalate, vanillate, isovanillate, veratrate, $2-$ and 3hydroxyphenylacetate (tested in this study, and ref. 1). Xenobiotic aromatic substrates for strain KF-1 known are the 4-sulfophenylcarboxylates $R / S$-3-(4-sulfophenyl)butyrate $\left(R / S-3-\mathrm{C}_{4}-\mathrm{SPC}\right), 3$ (4-sulfophenyl)- $\Delta 2$-enoylbutyrate (enoyl-3-C ${ }_{4}$ SPC), $R / S$-3-(4-sulfophenyl)pentanoate $\left(R / S-3-\mathrm{C}_{5}-\right.$ SPC), $\quad 3$-(4-sulfophenyl)- $\Delta 2$-enoylpentanoate (enoyl-3- $\mathrm{C}_{5}-\mathrm{SPC}$ ), as well as the three xenobiotic metabolites in the 3-C 4 -SPC-pathway, 4sulfoacetophenone (4-acetylbenzenesulfonate), 4- 
sulfophenol acetate, and 4-sulfophenol [1,9]. Finally, strain KF-1 did not utilize the following, other carbon sources tested (this study and refs. 1,9): $n$-alkanes $\left(\mathrm{C}_{6}-\mathrm{C}_{12}\right)$, cycloalkanes $\left(\mathrm{C}_{8}-\mathrm{C}_{12}\right)$, secondary-4-sulfophenylalkanes (LAS surfactants), secondary alkanesulfonates (SAS surfactants), dodecylsulfate (SDS surfactant), benzene sulfonate, 4-toluenesulfonate, 4-sulfobenzoate, phenylacetate, 3-phenylpropionate, 3- and 4phenylbutyrate, 4-sulfostyrene, 4-sulfobenzoate, 4-sulfocatechol, cyclohexanone, 4aminoacetophenone, gallic acid (3,4,5trihydroxybenzoic acid) and gallotannic acid, pentanesulfonate, isethionate, sulfoacetate, Dtartaric acid, acetamide, gamma-aminobutyrate, oxalate, methanol, methylamine, methanesulfonate or formate, and not 2- $\mathrm{C}_{4}-\mathrm{SPC}$ (2-[4-sulfophenyl] butyrate), 4- $\mathrm{C}_{5}-\mathrm{SPC}, 4-\mathrm{C}_{6}-\mathrm{SPC}$, $5-\mathrm{C}_{6}-\mathrm{SPC}$, or any of the $\mathrm{C}_{7}-\mathrm{C}_{9} \mathrm{SPC}$ generated during commercial LAS surfactant degradation.

C. testosteroni $\mathrm{KF}-1$ has been recognized for its poor ability to form structured biofilms on surfaces [71] [see also ref. 72], or micro- or macroscopic cellular aggregates in liquid cultures [73], in direct comparison to 'good' biofilm forming organisms such as Delftia acidovorans SPH-1 [71],
Pseudomonas aeruginosa PA01 [73], or C. testosteroni SPB-2 [1].

No significant production of siderophores could be observed for $C$. testosteroni KF-1 when grown in presence of non-inhibitory levels of iron chelator 2,2'-dipyridyl [see 74], in comparison to siderophore-producing Delftia acidovorans SPH-1, Pseudomonas aeruginosa PA01, and Pseudoalteromonas tunicata D2 [75] (reported in this study, data not shown).

Finally, strain KF-1 is able to grow in the presence of up to $500 \mu \mathrm{g} / \mathrm{ml}$ ampicillin or $600 \mu \mathrm{g} / \mathrm{ml}$ kanamycin in liquid cultures, as tested in this study.

\section{Phylogeny}

Based on its 16S rRNA gene sequence, strain KF-1 is a member of the genus Comamonas, which is placed in the family Comamonadaceae within the order Burkholderiales of Betaproteobacteria, as illustrated by a phylogenetic tree shown in Figure 2. Currently, 686 genome sequences of members of the order Burkholderiales of Betaproteobacteria, and 147 genome sequences within the family Comamonadaceae, have been, currently are, or are targeted to be established (GOLD database; May 2013).

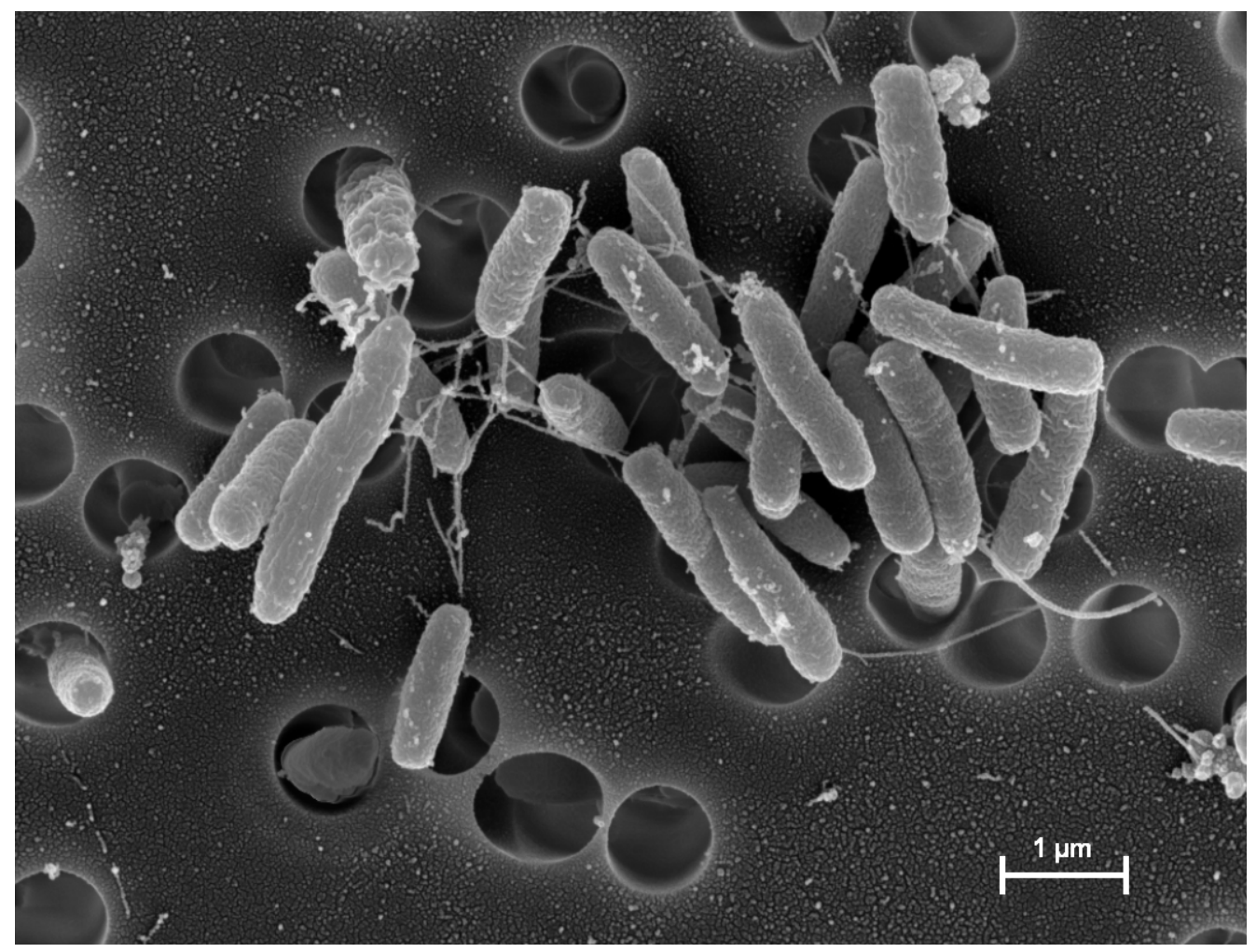

Figure 1. Scanning electron micrograph of Comamonas testosteroni KF-1. Cells derived from a liquid culture that grew in LB medium. 
Table 1. Classification and general features of Comamonas testosteroni KF-1 according to the MIGS recommendations [59].

\begin{tabular}{|c|c|c|c|}
\hline MIGS ID & Property & Term & Evidence code $^{\mathrm{a}}$ \\
\hline & & Domain Bacteria & TAS [60] \\
\hline & & Phylum Proteobacteria & TAS [61] \\
\hline & & Class Betaproteobacteria & TAS $[62,63]$ \\
\hline & Current classification & Order Burkholderiales & TAS $[62,64]$ \\
\hline & & Family Comamonadaceae & TAS [65] \\
\hline & & Genus Comamonas & TAS $[11,66-69]$ \\
\hline & & Species Comamonas testosteroni & TAS $[11,68]$ \\
\hline & & Strain KF-1 & TAS [1] \\
\hline & Gram stain & Negative & \\
\hline & Cell shape & small rod & \\
\hline & Motility & Motile & \\
\hline & Sporulation & non-sporulating & \\
\hline & Temperature range & Mesophile & TAS [1] \\
\hline & Optimum temperature & $30^{\circ} \mathrm{C}$ & TAS [1] \\
\hline & Carbon source & $\begin{array}{l}\text { 3-(4-sulfophenyl)butyrate }\left(3-\mathrm{C}_{4} \text {-SPC) and other SPCs }\right. \\
\text { [see text], 4-sulfoacetophenone, } 4 \text {-sulfophenyl ace- } \\
\text { tate, } 4 \text {-sulfophenol, testosterone, progesterone, } \\
\text { taurocholate, cholate, taurine, benzoate, } 4 \text { - } \\
\text { hydroxybenzoate, vanillate, isovanillate }\end{array}$ & IDA,TAS $[1,19]$ \\
\hline & Energy source & Chemoorganotroph & TAS $[1,6]$ \\
\hline & Terminal electron receptor & Molecular oxygen & TAS $[1,6]$ \\
\hline MIGS-6 & Habitat & Aerobic habitat & TAS $[1,6]$ \\
\hline MIGS-22 & Oxygen requirement & Aerobic & TAS $[1,6]$ \\
\hline MIGS-15 & Biotic relationship & free-living & TAS $[1,6]$ \\
\hline MIGS-14 & Pathogenicity & $\begin{array}{l}\text { Nonpathogenic, Risk group } 1 \text { (classification according } \\
\text { to German TRBA) }\end{array}$ & \\
\hline MIGS-4 & Geographic location & $\begin{array}{l}\text { isolated from a LAS surfactant-degrading laboratory } \\
\text { trickling filter (University of Konstanz, Germany) that } \\
\text { had been inoculated with sludge from a communal } \\
\text { sewage treatment plant (Herisau, Switzerland). }\end{array}$ & TAS $[1,6]$ \\
\hline MIGS-5 & Collection date & 1999 & TAS $[1,6]$ \\
\hline MIGS-4.1 & Latitude & $47^{\circ} 41^{\prime} 27.24^{\prime \prime}$ & TAS $[1,6]$ \\
\hline MIGS-4.2 & Longitude & $9^{\circ} 11^{\prime} 16.25^{\prime \prime}$ & TAS $[1,6]$ \\
\hline MIGS-4.4 & Altitude & $440 \mathrm{~m}$ & TAS $[1,6]$ \\
\hline
\end{tabular}

aEvidence codes - IDA: Inferred from Direct Assay; TAS: Traceable Author Statement; NAS: Non-traceable Author Statement. These evidence codes are from the Gene Ontology project [70]. If the evidence is IDA, then the property was directly observed for a live isolate by one of the authors or an expert mentioned in the acknowledgements. 


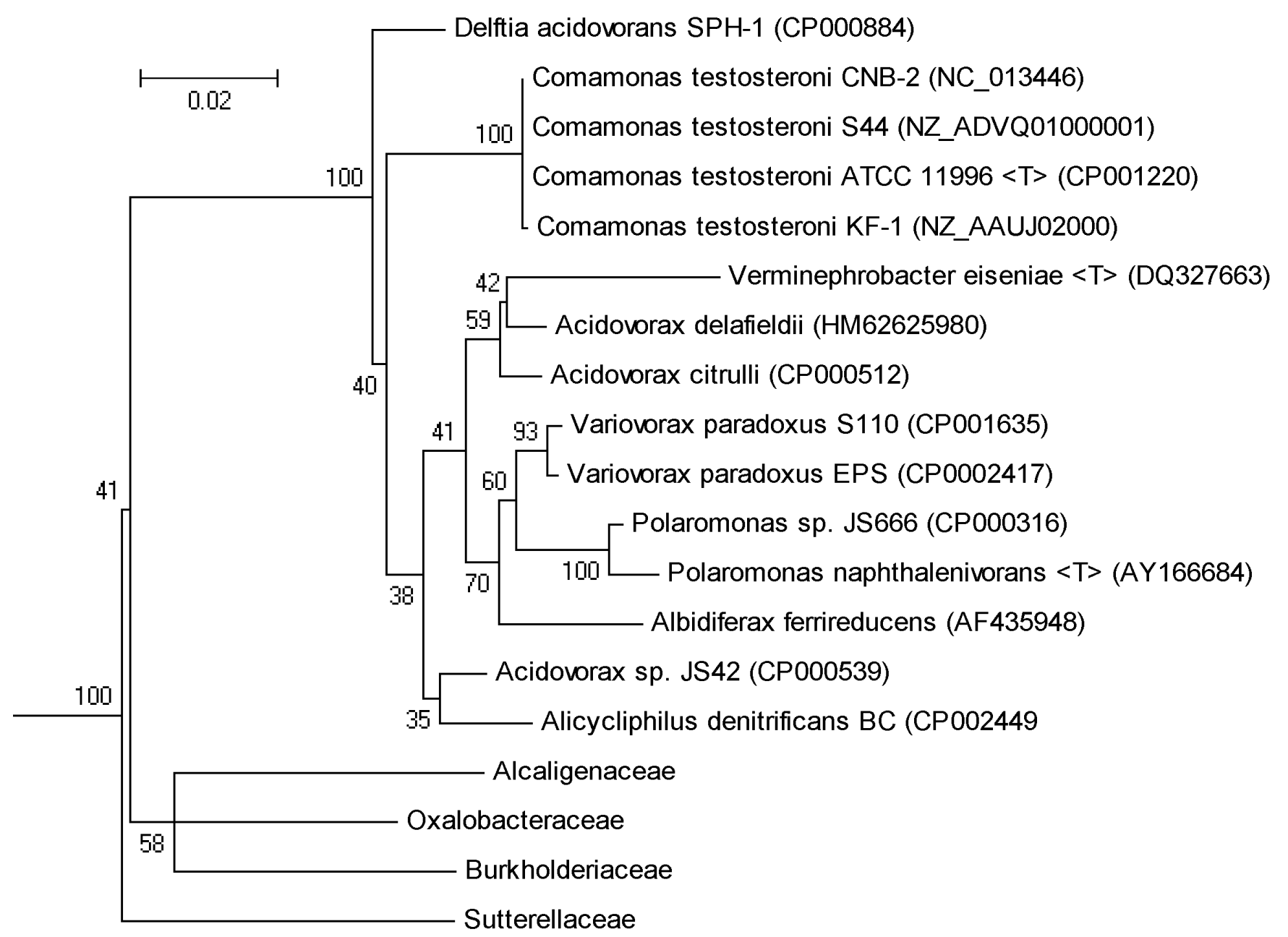

Figure 2. Illustration of the phylogenetic position of Comamonas testosteroni KF-1 within the order Burkholderiales of Betaproteobacteria. The $16 \mathrm{~S}$ rRNA gene alignment included the three other $C$. testosteroni strains whose genome sequences have been published, strain S44 [52], strain CNB-2 [24], and type-strain ATCC 11996 [22], and some of other genome-sequenced representatives of the family Comamonadaceae or of other families within the order Burkholderiales. The corresponding genome-project accession numbers, or $16 \mathrm{~S}$ rRNA gene accession numbers, are indicated. " $\mathrm{T}$ " indicates a type strain. The sequences were aligned using the RDP tree builder [76] and displayed using MEGA4 [77]. Bootstrap values are indicated; bar, 0.02 substitutions per nucleotide position.

\section{Genome sequencing information Genome project history}

The genome was selected for sequencing as part of the U.S. Department of Energy - Microbial Genomics Program 2006. The DNA sample was submitted in February 2006 and the initial sequencing phase was completed in July 2006. After the finishing and assembly phase the genome was presented for public access on January 2009; a modified version was presented (IMG) in August 2011. Table 2 presents the project information and its association with MIGS version 2.0 compliance [78].

\section{Growth conditions and DNA isolation}

Comamonas testosteroni KF-1, obtained from the Leibniz-Institut DSMZ-Deutsche Sammlung von Mikroorganismen und Zellkulturen (DSM14576), was grown on LB agar plates and transferred into selective medium (6 mM 4-sulfophenol/mineralsalts medium) in the 3-ml scale, and this culture was sub-cultivated in larger scale; cell pellets were stored frozen until DNA preparation. DNA was prepared following the JGI's DNA Isolation Bacterial CTAB Protocol. 


\section{Genome sequencing and assembly}

The genome of Comamonas testosteroni KF-1 was sequenced at the Joint Genome Institute (JGI) using a combination of $3.5 \mathrm{~kb}, 9 \mathrm{~kb}$ and $37 \mathrm{~kb}$ DNA libraries. All general aspects of library construction and sequencing performed at the JGI can be found at JGI website [79]. In total, 66.91 Mbp of Sanger sequence data were generated for the assembly from all three libraries, which provided for a 12.8-fold coverage of the genome. The Phred/Phrap/Consed software package was used for sequence assembly and quality assessment [80-82]. After the shotgun stage, reads were assembled with parallel phrap (High Performance
Software, LLC). Possible mis-assemblies were corrected with Dupfinisher [83], PCR amplification, or transposon bombing of bridging clones (Epicentre Biotechnologies, Madison, WI, USA). Gaps between contigs were closed by editing in Consed, custom primer walk or PCR amplification (Roche Applied Science, Indianapolis, IN, USA). The genome could not be closed due to clone viability issues, however, several clones circularized the contig, and a PCR product was obtained that spanned the ends, but all attempts at primer walking and transforming the amplicon were unsuccessful. At this time no additional work is planned for this project (labeled as Permanent Draft; one linear contig).

Table 2. Project information

\begin{tabular}{lll}
\hline MIGS ID & Property & Term \\
\hline MIGS-31.1 & Sequencing status & Complete \\
MIGS-28 & Libraries used & $3.5 \mathrm{~kb}, 9 \mathrm{~kb}$ and $37 \mathrm{~kb}$ DNA libraries \\
MIGS-29 & Sequencing platforms & Sanger \\
MIGS-31.2 & Sequencing depth & $12.8 \times$ \\
MIGS-30 & Assemblers & Phred/Phrap/Consed \\
MIGS-32 & Gene calling method & Prodigal \\
& Genbank ID & 17465 \\
& Genbank Date of Release & January 14, 2009 \\
& GOLD ID & Gi01330 \\
MIGS-13 & Source material identifier & DSM 14576 \\
& Project relevance & Biotechnological \\
\hline
\end{tabular}

\section{Genome annotation}

Genes were identified using Prodigal [84] as part of the genome annotation pipeline at Oak Ridge National Laboratory (ORNL), Oak Ridge, TN, USA, followed by a round of manual curation using the JGI GenePRIMP pipeline [85]. The predicted CDSs were translated and used to search the National Center for Biotechnology Information (NCBI) non-redundant database, UniProt, TIGRFam, Pfam, PRIAM, KEGG, COG, and InterPro databases. Non-coding genes and miscellaneous features were predicted using tRNAscan-SE [86], RNAMMer [87], Rfam [88], TMHMM [89], and signalP [90]. Additional gene prediction analysis and manual functional annotation was performed within the Integrated Microbial Genomes (IMG) platform [91] developed by the Joint Genome Institute, Walnut Creek, CA, USA [92].

\section{Genome properties}

The genome of $C$. testosteroni $\mathrm{KF}-1$ comprises a chromosome of $6,026,527$ bp $(61.76 \%$ GC content) (Table 3), for which a total number of 5,606 genes were predicted. Of these predicted genes, 5,492 are protein-coding genes, and 4,009 of the protein-coding genes were assigned to a putative function and the remaining annotated as hypothetical proteins. Genome analysis predicted 114 RNA genes and six rRNA operons. The properties and the statistics of the genome are summarized in Table 3 , the distribution of genes into COGs functional categories is presented in Table 4, and the chromosome map of the genome of $C$. testosteroni KF-1 is illustrated in Figure 3. 
The chromosome of $C$. testosteroni KF-1 (6.03 Mb) is larger in comparison to these of the three other C. testosteroni strains whose sequences have been published, of strain S44 [52] (5.53 Mb), strain CNB-2 [24] (5.46 Mb), and strain ATCC 11996 [22] (5.41 Mb), and in comparison to that of $C$. testosteroni NBRC 100989 (5.59 Mb) whose draft sequence has not yet been published (BioProject ID PRJNA70139). Upon genomic BLAST comparison however, the strain NBRC 100989 chromosome showed the highest similarity to the chromosome of $C$. testosteroni $\mathrm{KF}-1$.

For the three $C$. testosteroni genomes accessible within the IMG platform for direct comparison [57], strains KF-1, S44 and CNB-2, the gene abundance profile indicated, most strikingly, a much higher abundance of transposases (COG2801, COG2826 and COG4644) in strain KF-1 (42 total) in comparison to strains S44 (4 total) and CNB-2 (9 total); retroviral integrases (pfam00665) are more abundant in strain KF-1 (36 total) in comparison to strains S44 (none) and CNB-2 (13 total), and hemagluttinin repeat proteins (pfam05594) implicated in cell aggregation are more abundant (10 total) in comparison to strains S44 (none) and CNB-2 (none).

In respect to candidate genes encoding the metabolic features of $C$. testosteroni KF-1 (see above), almost identical (syntenic) gene clusters were found for the main steroid degradation genes characterized in C. testosteroni TA441 [16,17,20], including the genes characterized in $C$. testosteroni ATCC 11996 [18,21,52,93-95]; the strain KF-1 genes are up to $98 \%$ identical in their amino-acid sequences. Candidate genes for the degradation of the acyl-sidechain of cholate in Pseudomonas sp. strain Chol1 [96,97] were also found (thiolase, locus tag CtesDRAFT_PD3654; acyl-CoA dehydrogenase, PD3666), and the genes for inversion of the cholate-stereochemistry in Comamonas testosteroni TA441 [98] (PD3740-44). In respect to the complete degradation of taurocholate [19], several candidate genes for bile-salts hydrolase (taurocholate hydrolase) and candidate genes for the complete degradation of the taurine-moiety (2-aminoethanesulfonate) [19], e.g., for sulfoacetaldehyde acetyltransferase (Xsc, PD0776), were found.

Table 3. Nucleotide and gene count levels of the genome of C. testosteroni KF-1

\begin{tabular}{lrr}
\hline Attribute & Value & \% of total $^{\mathbf{a}}$ \\
\hline Genome size (bp) & $6,026,527$ & 100 \\
DNA coding region (bp) & $5,275,818$ & 87.54 \\
DNA G+C content (bp) & $3,723,913$ & 61.79 \\
Number of replicons & 1 & \\
Extrachromosomal elements & 0 & \\
Genes total number & 5,606 & 100 \\
Protein-coding genes & 5,492 & 97.97 \\
RNA genes & 114 & 2.03 \\
rRNA operon count & 6 & \\
Genes with function prediction & 4,009 & 71.51 \\
Genes in paralog clusters & 1314 & 23.44 \\
Genes assigned to COGs & 4,131 & 73.69 \\
Genes assigned to Pfam domains & 4,375 & 78.04 \\
Genes connected to KEGG pathways & 1,502 & 26.79 \\
Genes with transmembrane helices & 1,265 & 22.57 \\
Genes with signal peptides & 1,410 & 25.15 \\
\hline
\end{tabular}

a) The total is based on either the size of the genome in base pairs or the total number of protein coding genes in the annotated genome. 
Table 4. Number of genes associated with the general COG functional categories in C. testosteroni KF-1

\begin{tabular}{crrl}
\hline Code & Value & \%age & Description \\
\hline J & 187 & 4.02 & Translation, ribosomal structure and biogenesis \\
A & 2 & 0.04 & RNA processing and modification \\
K & 407 & 8.75 & Transcription \\
L & 212 & 4.56 & Replication, recombination and repair \\
B & 2 & 0.04 & Chromatin structure and dynamics \\
D & 32 & 0.69 & Cell cycle control, cell division, chromosome partitioning \\
Y & - & - & Nuclear structure \\
V & 53 & 1.14 & Defense mechanisms \\
T & 263 & 5.65 & Signal transduction mechanisms \\
M & 239 & 5.14 & Cell wall/membrane/envelope biogenesis \\
N & 102 & 2.19 & Cell motility \\
Z & - & - & Cytoskeleton \\
W & & & Extracellular structures \\
U & 159 & 3.42 & Intracellular trafficking, secretion, and vesicular transport \\
O & 154 & 3.31 & Posttranslational modification, protein turnover, chaperones \\
C & 304 & 6.54 & Energy production and conversion \\
G & 170 & 3.66 & Carbohydrate transport and metabolism \\
E & 361 & 7.76 & Amino acid transport and metabolism \\
F & 90 & 1.94 & Nucleotide transport and metabolism \\
H & 164 & 3.53 & Coenzyme transport and metabolism \\
I & 283 & 6.08 & Lipid transport and metabolism \\
P & 303 & 6.51 & Inorganic ion transport and metabolism \\
Q & 154 & 3.31 & Secondary metabolites biosynthesis, transport and catabolism \\
R & 546 & 11.74 & General function prediction only \\
S & 464 & 9.98 & Function unknown \\
NA & 1475 & 26.31 & Not in COGs \\
\hline & & & \\
\hline
\end{tabular}

a) The total is based on the total number of protein coding genes in the annotated genome.

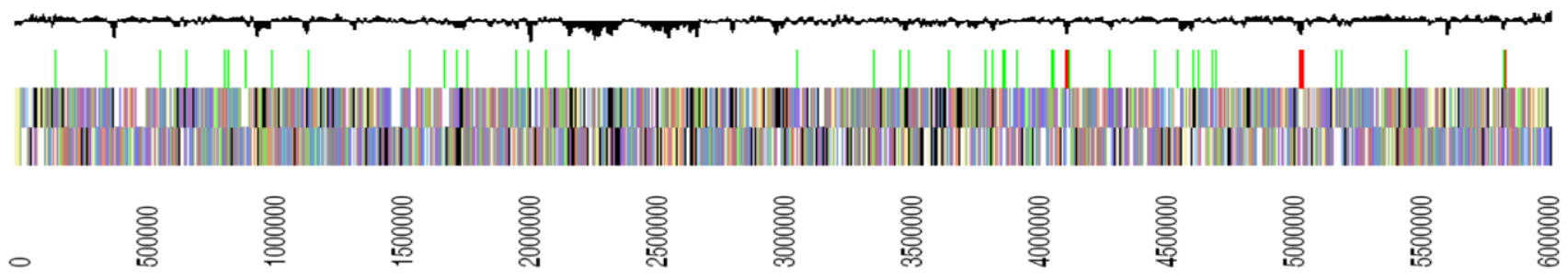

Figure 3. Chromosome map of the genome of $C$. testosteroni KF-1. From bottom to top: Genes on forward strand (colour by COG categories), genes on reverse strand (color by COG categories), RNA genes (tRNA, green; rRNA, red; other RNAs, black), GC content. 
Weiss et al.

Strain KF-1 has acquired the ability to utilize xenobiotic $3-\mathrm{C}_{4}-\mathrm{SPC}, 3-\mathrm{C}_{4}-\mathrm{SPC}-2 \mathrm{H}, 3-\mathrm{C}_{5}-\mathrm{SPC}$ and $3-\mathrm{C}_{5}-$ SPC-2H, 4-sulfoacetophenone (SAP), and 4sulfophenol (SP) (see above) [1,9]. The $3-\mathrm{C}_{4}$-SPC is converted to SAP [9] and further to 4-sulfophenol acetate (SPAc) by a recently identified BaeyerVilliger monooxygenase ('SAPMO', PD5437), and SPAc hydrolyzed by a recently identified carboxylester hydrolase encoded by the next gene in the genome (PD5438), to yield acetate and SP [10]. The two identified genes, together with other (predicted) catabolic genes, are framed by IS1071 insertion sequence elements (Tn3-family transposase genes), which suggests that these genes have only recently been acquired, possibly in the form of a 'catabolic composite transposon' through horizontal gene transfer [10]. Genes for other sections of the proposed 3- $\mathrm{C}_{4}-\mathrm{SPC}$ degradation pathway in strain KF-1, i.e., the 'upper' and 'lower' pathway, from 3-C $\mathrm{C}_{4}$-SPC to SAP and from SP further to central metabolites, respectively [9], are examined in our present work (unpublished).

C. testosteroni KF-1 encodes a wealth of genes for aromatic ring-cleavage oxygenases and aromaticring hydroxylating oxygenase (systems), as commonly observed for members of the order Burkholderiales [99]. Firstly, the complete protocatechuate 4,5-cleavage (meta) degradation operon (pmd-operon) characterized in $C$. testosteroni strain BR6020 [35,43], strain E6 [47] and CNB-1 [48] involved in the degradation pathways for vanillate, isovanillate and 3 - and 4hydroxybenzoate, was found in strain KF-1 ( $p m d B$, PD1898) (and two pmdB paralogs, PD1614 and 1810). An ortholog of the 3-hydroxybenzoate monooxygenase characterized in $C$. testosteroni GZ39 [100] was found in strain KF-1 (PD1242), as were the genes for conversion of vanillate and isovanillate (vanA/ivaA: PD0400/PD0403) [43].

Gene clusters of the meta-pathway enzymes for degradation of phenol as characterized in $C$. testosteroni TA441, i.e., aphCEFGHJI [101] and aphKLMNOPQB [102]), were not found in strain KF1 , but in strains S44 and CNB-2. However, homologs for all meta-pathway enzymes (corresponding to aphCEFGHJI) seem to be distributed at different locations in the strain KF-1 genome, but a valid candidate gene cluster of the phenol hydroxylase components (aph- [102] or phcKLMNOP [34] genes) and catechol 2,3-dioxygenase $(a p h B)$ could not be found in the strain KF-1 genome. Also the gene cluster for the 3-(3-hydroxyphenyl) propionic acid degradation pathway ( $m h p$-operon) characterized in Comamonas testosteroni TA441 [103] was not found in the genome of strain KF-1, nor in strain CNB-2, but was found in strain S44; homologs for all pathway enzymes (corresponding to $m h p A B D F E$ ) seem to be distributed at different locations in the strain KF-1 genome.

An almost identical gene cluster for the terepthalate (benzene-1,4-dicarboxylic acid) pathway ( $t p h$-cluster) as characterized in C. testosteroni YZW-D [104] and strain E6 [44,46] was found in strain KF-1 (tphA, PD2130). The gene cluster for the isophthalate (benzene-1,3-dicarboxylic acid) pathway of C. testosteroni YZW-D [104] and strain E6 [45] was also found in strain KF-1 (iphA, PD2139), encoded directly upstream of the tphcluster. Notably, at least nine other Rieske-domain ring-hydroxylating oxygenase component genes (COG4638) similar to tpaA/iphA (PD2130/PD2139) and vanA/ivaA (see above, PD0400/PD0403), seem to be encoded in strain KF-1 (PD2042, 1888, 4205, 2022, 0968, 3693, $1612,2032,5293)$.

No ortholog of the catechol 2,3-ring cleavage dioxygenase (non-heme $\mathrm{Fe}^{2+}$ ) of the phenolpathway gene cluster $(a p h B)$ [102] was found in strain KF-1, but two other class I/II extradiol ringcleavage dioxygenase candidates (PD0021, 5290) in addition to a (decarboxylating) 4hydroxyphenylpyruvate dioxygenase candidate (PD0347) (also in CNB-2 and S44), tesB of the steroid gene cluster (PD3739), and the class-III type extradiol ring-cleavage dioxygenases mentioned above (PmdAB) were found.

In respect to intradiol ring-cleavage dioxygenases, three candidates for (non-heme $\mathrm{Fe}^{3+}$ ) catechol 1,2dioxygenase/protocatechuate 3,4-dioxygenase beta subunit/hydroxyquinol 1,2-dioxygenase were found in strain KF-1, i.e., PD0424, 5469, and 5471; notably, the latter two candidates are not represented in strains CNB-2 and S44.

Also not represented in the $C$. testosteroni $\mathrm{KF}-1$ genome is the nitrobenzene $(\mathrm{nbz})$ degradation gene cluster of Comamonas sp. JS765 [38], the 3nitrobenzoate $(\mathrm{mnb})$ degradation cluster of $C$. testosteroni BR6020 [23], the 4-chlorobenzoate uptake and degradation cluster of Comamonas $s p$. strain DJ-12 [51,105], and not the 4chloronitrobenzene $(\mathrm{cnb})$ cluster on plasmid pCNB1 in C. testosteroni CNB-1 [49] and the upperpathway chloroaniline $(\mathrm{dca})$ cluster on plasmid pWDL7 in C. testosteroni WDL7 [26]. Finally, an 
ortholog of the aliphatic nitrilase/cyanide hydratase (NitA) characterized in a C. testosteroni soil isolate [106] was also not found in the genome of strain KF-1, nor in those of CNB-2 or S44.

Strain KF-1 utilized none of the sugars tested (see above), and this observation is reflected by an absence of appropriate candidate genes in strain KF1 for hexokinase and glucokinase in glycolysis, as well as of genes of the oxidative branch of the pentose phosphate pathway, as reported also for $C$. testosteroni CNB-2 [24].

Strain KF-1 is able to utilize nicotinate for growth and encodes an orthologous set of genes for the nicotinate dehydrogenase /hydroxylase complex (PD0815-13) characterized in C. testosteroni JA1 [107].

The poly(3-hydroxybutyrate) (PHB) biosynthesis and utilization operon of Comamonas sp. EB172 [108] is also encoded in strain KF-1 (e.g., PD2272). Furthermore, strain KF-1 tested positive for growth with extracellular poly(3hydroxybutyrate) (this study), and strain KF-1 encodes an ortholog (PD3795) of the characterized poly(3-hydroxybutyrate) depolymerase

\section{Acknowledgements}

We thank Joachim Hentschel for SEM operation, and several students of our practical classes for testing growth substrates. The work was financially supported by the University of Konstanz and the Konstanz Research School Chemical Biology, the University of New South Wales and the Centre for Marine Bio-Innovation, and by the Deutsche Forschungsgemeinschaft (DFG grant SCHL 1936/1-1 to D.S.). The work conducted by the U.S. Department of Energy Joint Genome Institute

\section{References}

1. Schleheck D, Knepper TP, Fischer K, Cook AM. Mineralization of individual congeners of linear alkylbenzenesulfonate by defined pairs of heterotrophic bacteria. Appl Environ Microbiol 2004;

70:4053-4063. PubMed

http://dx.doi.org/10.1128/AEM.70.7.4053-

4063.2004

2. Knepper TP, Barceló D, deVoogt P. Analysis and fate of surfactants in the quatic environment. Amsterdam: Elsevier; 2003.

3. Swisher RD. Surfactant biodegradation. New York: Marcel Dekker; 1970.

4. Schleheck D, Weiss M, Pitluck S, Bruce D, Land ML, Han S, Saunders E, Tapia R, Detter C, Brettin $\mathrm{T}$, et al. Complete genome sequence of precursor (PhaZ) of Comamonas sp. strain 31A [109]; notably, the ortholog was also found in $C$. testosteroni ATCC 11996', but not in strains S44 and CNB-2.

In respect to the ampicillin (beta-lactam) antibiotic resistance of strain $\mathrm{KF}-1$, the genome encodes at least two beta-lactamase class A (PD2722, 4357) and one beta-lactamase class B (PD0340) candidates, and with respect to kanamycin (aminoglycoside) resistance, two aminoglycoside phosphotransferase candidates (PD3717, 1418); notably, the latter two are not represented in strains CNB-2 and S44.

All four heavy metal exporter ATPase genes (zntA) and five CzcA-family exporter gene clusters described for highly zinc-resistant $C$. testosteroni S44 [52] were found in strain KF-1, and in total eight zntA and 11 cntA candidates. Two arsenical resistance gene clusters (PD1708-06 and 3544-42), each with candidates for arsenical pump (ArsB), arsenate reductase (ArsC), NADPH:FMN oxidoreductases (ArsH), and transcriptional regulator (ArsR), and a third arsC candidate (PD0567), were found in strain KF-1.

was supported by the Office of Science of the U.S. Department of Energy under Contract No. DE-AC0205CH11231, and by the University of California, Lawrence Berkeley National Laboratory under contract No. W-7405-Eng-48, Lawrence Berkeley National Laboratory under contract No. DE-AC03-76SF00098 and Los Alamos National Laboratory under contract No. W7405-ENG-36.

Parvibaculum lavamentivorans type strain (DS- $\left.1^{\top}\right)$. Stand Genomic Sci 2011; 5:298-310. PubMed http://dx.doi.org/10.4056/sigs.2215005

5. Schleheck D, Dong W, Denger K, Heinzle E, Cook AM. An alpha-proteobacterium converts linear alkylbenzenesulfonate surfactants into sulfophenylcarboxylates and linear alkyldiphenyletherdisulfonate surfactants into sulfodiphenylethercarboxylates. Appl Environ Microbiol 2000; 66:1911-1916. PubMed http://dx.doi.org/10.1128/AEM.66.5.1911$\underline{1916.2000}$

6. Dong W, Eichhorn P, Radajewski S, Schleheck D, Denger K, Knepper TP, Murrell JC, Cook AM. Parvibaculum lavamentivorans converts linear 
alkylbenzenesulphonate surfactant to sulphophenylcarboxylates, alpha,betaunsaturated sulphophenylcarboxylates and sulphophenyldicarboxylates, which are degraded in communities. J Appl Microbiol 2004; 96:630640. PubMed http://dx.doi.org/10.1111/j.13652672.2004.02200.x

7. Schleheck D, Tindall BJ, Rossello-Mora R, Cook AM. Parvibaculum lavamentivorans gen. nov., sp. nov., a novel heterotroph that initiates catabolism of linear alkylbenzenesulfonate. Int J Syst Evol Microbiol 2004; 54:1489-1497. PubMed http://dx.doi.org/10.1099/ijs.0.03020-0

8. Schleheck D, Knepper TP, Eichhorn P, Cook AM. Parvibaculum lavamentivorans DS $-1^{\top}$ degrades centrally substituted congeners of commercial linear alkylbenzenesulfonate to sulfophenyl carboxylates and sulfophenyl dicarboxylates. Appl Environ Microbiol 2007; 73:4725-4732. PubMed http://dx.doi.org/10.1128/AEM.00632-07

9. Schleheck D, von Netzer F, Fleischmann T, Rentsch D, Huhn T, Cook AM, Kohler HP. The missing link in linear alkylbenzenesulfonate surfactant degradation: 4-sulfoacetophenone as a transient intermediate in the degradation of 3-(4sulfophenyl)butyrate by Comamonas testosteroni KF-1. Appl Environ Microbiol 2010; 76:196-202. PubMed http://dx.doi.org/10.1128/AEM.02181-09

10. Weiss M, Denger K, Huhn T, Schleheck D. Two enzymes of a complete degradation pathway for linear alkylbenzenesulfonate (LAS) surfactants: 4sulfoacetophenone Baeyer-Villiger monooxygenase and 4-sulfophenylacetate esterase in Comamonas testosteroni KF-1. Appl Environ Microbiol 2012; 78:8254-8263. PubMed http://dx.doi.org/10.1128/AEM.02412-12

11. Tamaoka J, Ha DM, Komagata K. Reclassification of Pseudomonas acidovorans Den Dooren De Jong 1926 and Pseudomonas testosteroni Marcus and Talalay 1956 as Comamonas acidovorans comb. nov. and Comamonas testosteroni comb. nov., with an emended description of the genus Comamonas. Int J Syst Bacteriol 1987; 37:52-59. http://dx.doi.org/10.1099/00207713-37-1-52

12. Talalay P, Dobson MM, Tapley DF. Oxidative degradation of testosterone by adaptive enzymes. Nature 1952; 170:620-621. PubMed http://dx.doi.org/10.1038/170620a0

13. Talalay P. A fascination with enzymes: The journey not the arrival matters. J Biol Chem 2005; 280:28829-28847. PubMed http://dx.doi.org/10.1074/jbc.X500004200
14. Shaw DA, Borkenhagen LF, Talalay P. Enzymatic oxidation of steroids by cell-free extracts of Pseudomonas testosteroni: isolation of cleavage products of ring A. Proc Natl Acad Sci USA 1965; 54:837-844. PubMed http://dx.doi.org/10.1073/pnas.54.3.837

15. Marcus PI, Talalay P. Induction and purification of alpha- and beta-hydroxysteroid dehydrogenases. J Biol Chem 1956; 218:661-674. PubMed

16. Horinouchi M, Yamamoto T, Taguchi K, Arai $H$, Kudo T. Meta-cleavage enzyme gene tes $B$ is necessary for testosterone degradation in Comamonas testosteroni TA441. Microbiology 2001; 147:3367-3375. PubMed

17. Horinouchi M, Hayashi T, Yamamoto T, Kudo T. A new bacterial steroid degradation gene cluster in Comamonas testosteroni TA441 which consists of aromatic-compound degradation genes for seco-steroids and 3-ketosteroid dehydrogenase genes. Appl Environ Microbiol 2003; 69:44214430. PubMed http://dx.doi.org/10.1128/AEM.69.8.44214430.2003

18. Xiong G, Martin HJ, Maser E. Identification and characterization of a novel translational repressor of the steroid-inducible 3 alpha-hydroxysteroid dehydrogenase/carbonyl reductase gene in Comamonas testosteroni. J Biol Chem 2003; 278:47400-47407. PubMed http://dx.doi.org/10.1074/jbc.M309210200

19. Rösch V, Denger K, Schleheck D, Smits TH, Cook AM. Different bacterial strategies to degrade taurocholate. Arch Microbiol 2008; 190:11-18. PubMed http://dx.doi.org/10.1007/s00203-008$\underline{0357-7}$

20. Horinouchi M, Kurita T, Hayashi T, Kudo T. Steroid degradation genes in Comamonas testosteroni TA441: Isolation of genes encoding a delta 4(5)isomerase and 3 alpha- and 3 betadehydrogenases and evidence for a $100 \mathrm{~kb}$ steroid degradation gene hot spot. I Steroid Biochem Mol Biol 2010; 122:253-263. PubMed http://dx.doi.org/10.1016/j.jsbmb.2010.06.002

21. Gong W, Xiong G, Maser E. Identification and characterization of the LysR-type transcriptional regulator HsdR for steroid-inducible expression of the 3alpha-hydroxysteroid dehydrogenase/carbonyl reductase gene in Comamonas testosteroni. Appl Environ Microbiol 2012; 78:941-950. PubMed http://dx.doi.org/10.1128/AEM.06872-11 
22. Gong W, Kisiela M, Schilhabel MB, Xiong G, Maser $\mathrm{E}$. Genome sequence of Comamonas testosteroni ATCC 11996, a representative strain involved in steroid degradation. J Bacteriol 2012; 194:1633-1634. PubMed http://dx.doi.org/10.1128//B.06795-11

23. Providenti MA, Shaye RE, Lynes KD, McKenna NT, O'Brien JM, Rosolen S, Wyndham RC, Lambert LB. The locus coding for the 3-nitrobenzoate dioxygenase of Comamonas sp. strain JS46 is flanked by IS1071 elements and is subject to deletion and inversion events. App/ Environ Microbiol 2006; 72:2651-2660. PubMed http://dx.doi.org/10.1128/AEM.72.4.26512660.2006

24. Ma YF, Zhang Y, Zhang JY, Chen DW, Zhu YQ, Zheng HJ, Wang SY, Jiang CY, Zhao GP, Liu SJ. The complete genome of Comamonas testosteroni reveals its genetic adaptations to changing environments. Appl Environ Microbiol 2009; 75:68126819. PubMed http://dx.doi.org/10.1128/AEM.00933-09

25. Locher HH, Leisinger TAMC. Degradation of $p$ toluenesulphonic acid via sidechain oxidation, desulphonation and meta ring cleavage in $P_{s e u-}$ domonas (Comamonas) testosteroni T-2. J Gen Microbiol 1989; 135:1969-1978. PubMed

26. Krol JE, Penrod JT, McCaslin H, Rogers LM, Yano $\mathrm{H}$, Stancik AD, Dejonghe W, Brown CJ, Parales RE, Wuertz S, et al. Role of IncP-1 beta plasmids pWDL7:rfp and pNB8c in chloroaniline catabolism as determined by genomic and functional analyses. Appl Environ Microbiol 2012; 78:828838. PubMed http://dx.doi.org/10.1128/AEM.07480-11

27. Nishino SF, Spain JC. Oxidative pathway for the biodegradation of nitrobenzene by Comamonas sp. strain JS765. Appl Environ Microbiol 1995; 61:2308-2313. PubMed

28. Chen YH, Chai LY, Zhu YH, Yang ZH, Zheng Y, Zhang $\mathrm{H}$. Biodegradation of kraft lignin by a bacterial strain Comamonas sp. B-9 isolated from eroded bamboo slips. J App/ Microbiol 2012; 112:900-906. PubMed http://dx.doi.org/10.1111/j.13652672.2012.05275.x

29. Ahmad D, Massé R, Sylvestre M. Cloning and expression of genes involved in 4-chlorobiphenyl transformation by Pseudomonas testosteroni: homology to polychlorobiphenyl-degrading genes in other bacteria. Gene 1990; 86:53-61. PubMed http://dx.doi.org/10.1016/0378-1119(90)90113-6
30. Wang Y, Yamazoe A, Suzuki S, Liu CT, Aono T, Oyaizu $\mathrm{H}$. Isolation and characterization of dibenzofuran-degrading Comamonas sp. strains isolated from white clover roots. Curr Microbiol 2004; 49:288-294. PubMed http://dx.doi.org/10.1007/s00284-004-4348-x

31. Song Z, Edwards SR, Burns RG. Biodegradation of naphthalene-2-sulfonic acid present in tannery wastewater by bacterial isolates Arthrobacter sp. $2 \mathrm{AC}$ and Comamonas sp. 4BC. Biodegradation 2005; •••:237-252. PubMed http://dx.doi.org/10.1007/s10532-004-0889-8

32. Ornston MK, Ornston LN. Regulation of betaketoadipate pathway in Pseudomonas acidovorans and Pseudomonas testosteroni. J Gen Microbiol 1972; 73:455-464. PubMed http://dx.doi.org/10.1099/00221287-73-3-455

33. Schläfli HR, Weiss MA, Leisinger T, Cook AM. Terephthalate 1,2-dioxygenase system from Comamonas testosteroni T-2 - Purification and some properties of the oxygenase component. I Bacteriol 1994; 176:6644-6652. PubMed

34. Teramoto $\mathrm{M}$, Futamata $\mathrm{H}$, Harayama $\mathrm{S}$, Watanabe K. Characterization of a high-affinity phenol hydroxylase from Comamonas testosteroni R5 by gene cloning, and expression in Pseudomonas aeruginosa PAO1c. Mol Gen Genet 1999; 262:552-558. PubMed http://dx.doi.org/10.1007/s004380051117

35. Providenti MA, Mampel J, MacSween S, Cook AM, Wyndham RC. Comamonas testosteroni BR6020 possesses a single genetic locus for extradiol cleavage of protocatechuate. Microbiology-Sgm 2001; 147:2157-2167. PubMed

36. Sylvestre $M$, Sirois $M$, Hurtubise $Y$, Bergeron J, Ahmad D, Shareck F, Barriault D, Guillemette I, Juteau JM. Sequencing of Comamonas testosteroni strain B-356-biphenyl/chlorobiphenyl dioxygenase genes: evolutionary relationships among Gram-negative bacterial biphenyl dioxygenases. Gene 1996; 174:195-202. PubMed http://dx.doi.org/10.1016/0378-1119(96)00039-X

37. Tralau T, Cook AM, Ruff J. Map of the IncP1beta plasmid pTSA encoding the widespread genes (tsa) for $p$-toluenesulfonate degradation in Comamonas testosteroni T-2. Appl Environ Microbiol 2001; 67:1508-1516. PubMed http://dx.doi.org/10.1128/AEM.67.4.1508$\underline{1516.2001}$

38. Lessner DJ, Johnson GR, Parales RE, Spain JC, Gibson DT. Molecular characterization and substrate specificity of nitrobenzene dioxygenase 
from Comamonas sp. strain JS765. Appl Environ

Microbiol 2002; 68:634-641. PubMed

http://dx.doi.org/10.1128/AEM.68.2.634$\underline{641.2002}$

39. Tralau T, Cook AM, Ruff J. An additional regulator, $\mathrm{TsaQ}$, is involved with $\mathrm{TsaR}$ in regulation of transport during the degradation of $p$ toluenesulfonate in Comamonas testosteroni T-2. Arch Microbiol 2003; 180:319-326. PubMed http://dx.doi.org/10.1007/s00203-003-0594-8

40. Tralau T, Mampel J, Cook AM, Ruff J. Characterization of TsaR, an oxygen-sensitive LysR-type regulator for the degradation of $p$ toluenesulfonate in Comamonas testosteroni T-2. Appl Environ Microbiol 2003; 69:2298-2305. $\underline{\text { PubMed }}$ http://dx.doi.org/10.1128/AEM.69.4.22982305.2003

41. Mampel J, Maier E, Tralau T, Ruff J, Benz R, Cook AM. A novel outer-membrane anion channel (porin) as part of a putatively two-component transport system for 4-toluenesulphonate in Comamonas testosteroni T-2. Biochem J 2004; 383:91-99. PubMed http://dx.doi.org/10.1042/BJ20040652

42. Mampel J, Providenti MA, Cook AM. Protocatechuate 4,5-dioxygenase from Comamonas testosteroni T-2: biochemical and molecular properties of a new subgroup within class III of extradiol dioxygenases. Arch Microbiol 2005; 183:130-139. PubMed http://dx.doi.org/10.1007/s00203-004-0755-4

43. Providenti MA, O'Brien JM, Ruff J, Cook AM, Lambert IB. Metabolism of isovanillate, vanillate, and veratrate by Comamonas testosteroni strain BR6020. J Bacteriol 2006; 188:3862-3869. PubMed http://dx.doi.org/10.1128/JB.01675-05

44. Sasoh M, Masai E, Ishibashi S, Hara H, Kamimura N, Miyauchi K, Fukuda M. Characterization of the terephthalate degradation genes of Comamonas sp. strain E6. Appl Environ Microbiol 2006; 72:1825-1832. PubMed http://dx.doi.org/10.1128/AEM.72.3.1825$\underline{1832.2006}$

45. Fukuhara Y, Inakazu K, Kodama N, Kamimura N, Kasai D, Katayama Y, Fukuda M, Masai E. Characterization of the isophthalate degradation genes of Comamonas sp. strain E6. Appl Environ Microbiol 2010; 76:519-527. PubMed http://dx.doi.org/10.1128/AEM.01270-09

46. Kasai D, Kitajima M, Fukuda M, Masai E. Transcriptional regulation of the terephthalate catabo- lism operon in Comamonas sp. strain E6. Appl Environ Microbiol 2010; 76:6047-6055. PubMed http://dx.doi.org/10.1128/AEM.00742-10

47. Kamimura N, Aoyama T, Yoshida R, Takahashi K, Kasai D, Abe T, Mase K, Katayama Y, Fukuda M, Masai E. Characterization of the protocatechuate 4,5-cleavage pathway operon in Comamonas sp. strain E6 and discovery of a novel pathway gene. Appl Environ Microbiol 2010; 76:8093-8101. PubMed http://dx.doi.org/10.1128/AEM.01863-10

48. Ni B, Zhang Y, Chen DW, Wang BJ, Liu SJ. Assimilation of aromatic compounds by Comamonas testosteroni: characterization and spreadability of protocatechuate 4,5-cleavage pathway in bacteria. Appl Microbiol Biotechnol 2012. PubMed http://dx.doi.org/10.1007/s00253012-4402-8

49. Ma YF, Wu JF, Wang SY, Jiang CY, Zhang Y, Qi SW, Liu L, Zhao GP, Liu SJ. Nucleotide sequence of plasmid pCNB1 from Comamonas strain CNB1 reveals novel genetic organization and evolution for 4-chloronitrobenzene degradation. Appl Environ Microbiol 2007; 73:4477-4483. PubMed http://dx.doi.org/10.1128/AEM.00616-07

50. Zhang Y, Ma YF, Qi SW, Meng B, Chaudhry MT, Liu SQ, Liu SJ. Responses to arsenate stress by Comamonas sp strain CNB-1 at genetic and proteomic levels. Microbiology-Sgm 2007; 153:37133721. PubMed http://dx.doi.org/10.1099/mic.0.2007/011403-0

51. Cai L, Liu G, Rensing C, Wang G. Genes involved in arsenic transformation and resistance associated with different levels of arsenic-contaminated soils. BMC Microbiol 2009; 9:4. PubMed http://dx.doi.org/10.1186/1471-2180-9-4

52. Xiong J, Li D, Li H, He M, Miller SJ, Yu L, Rensing C, Wang G. Genome analysis and characterization of zinc efflux systems of a highly zincresistant bacterium, Comamonas testosteroni S44. Res Microbiol 2011; 162:671-679. PubMed http://dx.doi.org/10.1016/j.resmic.2011.06.002

53. Siunova TV, Siunov AV, Kochetkov VV, Boronin AM. The cnr-like operon in strain Comamonas sp. encoding resistance to cobalt and nickel. Genetika 2009; 45:336-341. PubMed

54. Turek M, Vilimkova L, Kremlackova V, Paca JJ, Halecky M, Paca J, Stiborova M. Isolation and partial characterization of extracellular NADPHdependent phenol hydroxylase oxidizing phenol to catechol in Comamonas testosteroni. Neuroendocrinol Lett 2011; 32:137-145. PubMed 
55. Godocíková J, Bohácová V, Zámocký M, Polek B. Production of catalases by Comamonas spp. and resistance to oxidative stress. Folia Microbiol (Praha) 2005; 50:113-118. PubMed http://dx.doi.org/10.1007/BF02931458

56. Oppermann UC, Belai I, Maser E. Antibiotic resistance and enhanced insecticide catabolism as consequences of steroid induction in the gramnegative bacterium Comamonas testosteroni. J Steroid Biochem Mol Biol 1996; 58:217-223. PubMed http://dx.doi.org/10.1016/09600760(96)00021-0

57. Markowitz VM, Chen IMA. Palaniappan, Chu K, Szeto E, Grechkin Y, Ratner A, Jacob B, Huang J, Williams $P$ and others. IMG: the integrated microbial genomes database and comparative analysis system. Nucleic Acids Res 2012; 40:D115D122. PubMed http://dx.doi.org/10.1093/nar/gkr1044

58. Thurnheer $\mathrm{T}$, Kohler T, Cook AM, Leisinger T. Orthanilic acid and analogs as carbon-sources for bacteria - Growth physiology and enzymatic desulfonation. / Gen Microbiol 1986; 132:12151220.

59. Field D, Garrity GM, Gray T, Morrison N, Selengut J, Sterk P, Tatusova T, Thomson N, Allen MJ, Angiuoli SV, et al. The minimum information about a genome sequence (MIGS) specification. Nat Biotechnol 2008; 26:541-547. PubMed http://dx.doi.org/10.1038/nbt1360

60. Woese CR, Kandler O, Wheelis ML. Towards a natural system of organisms: proposal for the domains Archaea, Bacteria, and Eucarya. Proc Natl Acad Sci USA 1990; 87:4576-4579. PubMed http://dx.doi.org/10.1073/pnas.87.12.4576

61. Garrity GM, Bell JA, Lilburn T. Phylum XIV. Proteobacteria phyl. nov. In: Garrity GM, Brenner DJ, Krieg NR, Staley JT (eds), Bergey's Manual of Systematic Bacteriology, Second Edition, Volume 2, Part B, Springer, New York, 2005, p. 1.

62. Validation List No. 107. List of new names and new combinations previously effectively, but not validly, published. Int I Syst Evol Microbiol 2006; 56:1-6. PubMed http://dx.doi.org/10.1099/ijs.0.64188-0

63. Garrity GM, Bell JA, Lilburn T. Class II. Betaproteobacteria class. nov. In: Garrity GM, Brenner DJ, Krieg NR, Staley JT (eds), Bergey's Manual of Systematic Bacteriology, Second Edition, Volume 2, Part C, Springer, New York, 2005, p. 575.
64. Garrity GM, Bell JA, Lilburn T. Order I. Burkholderiales ord. nov. In: Garrity GM, Brenner DJ, Krieg NR, Staley JT (eds), Bergey's Manual of Systematic Bacteriology, Second Edition, Volume 2, Part C, Springer, New York, 2005, p. 575.

65. Willems A, De Ley J, Gillis M, Kersters K. Comamonadaceae, a new family encompassing the acidovorans rRNA complex, including Variovorax paradoxus gen. nov., comb. nov., for Alcaligenes paradoxus (Davis 1969). Int J Syst Bacteriol 1991; 41:445-450. http://dx.doi.org/10.1099/00207713-41-3-445

66. De Vos P, Kersters K, Gillis M, Segers P, de Ley J. Comamonas Davis and Park 1962 gen. nov., nom. rev. emend., and Comamonas terrigena Hugh 1962 sp. nov., nom. rev. Int J Syst Bacteriol 1985; 35:443-453. http://dx.doi.org/10.1099/00207713-35-4-443

67. Zhang J, Wang Y, Zhou S, Wu C, He J, Li F. Comamonas guangdongensis sp. nov., isolated from subterranean forest sediment, and emended description of the genus Comamonas. Int I Syst Evol Microbiol 2013; 63:809-814. PubMed http://dx.doi.org/10.1099/ijs.0.040188-0

68. Willems A, Pot B, Falsen E, Vandamme P, Gillis $M$, Kersters K, de Ley J. Polyphasic taxonomic study of the emended genus Comamonas: relationship to Aquaspirillum aquaticum, E. Falsen group 10, and other clinical isolates. Int J Syst Bacteriol 1991; 41:427-444. http://dx.doi.org/10.1099/00207713-41-3-427

69. Davis GHG, Park RWA. A taxonomic study of certain bacteria currently classified as Vibrio species. J Gen Microbiol 1962; 27:101-119. PubMed http://dx.doi.org/10.1099/00221287-27-1-101

70. Ashburner M, Ball CA, Blake JA, Botstein D, Butler H, Cherry JM, Davis AP, Dolinski K, Dwight SS, Eppig JT, et al. Gene Ontology: tool for the unification of biology. Nat Genet 2000; 25:25-29. PubMed http://dx.doi.org/10.1038/75556

71. Buhmann M. Charakterisierung der Biofilmbildung durch eine Tensid-abbauende Bakteriengemeinschaft [Master's thesis]. Konstanz: University of Konstanz; 2008. 126 p.

72. Li M, Peng L, Ji Z, Xu J, Li S. Establishment and characterization of dual-species biofilms formed from a 3,5-dinitrobenzoic-degrading strain and bacteria with high biofilm-forming capabilities. FEMS Microbiol Lett 2008; 278:15-21. PubMed http://dx.doi.org/10.1111/j.15746968.2007.00913.x 
73. Schleheck D, Barraud N, Klebensberger J, Webb JS, McDougald D, Rice SA, Kjelleberg S. Pseudomonas aeruginosa $\mathrm{PAO} 1$ preferentially grows as aggregates in liquid batch cultures and disperses upon starvation. PLOS ONE 2009; 4:e5513. PubMed

http://dx.doi.org/10.1371/journal.pone.0005513

74. Stelzer S, Egan S, Larsen MR, Bartlett DH, Kjelleberg S. Unravelling the role of the ToxR-like transcriptional regulator $\mathrm{WmpR}$ in the marine antifouling bacterium Pseudoalteromonas tunicata. Microbiology 2006; 152:1385-1394. PubMed http://dx.doi.org/10.1099/mic.0.28740-0

75. Thomas T, Evans FF, Schleheck D, Mai-Prochnow A, Burke C, Penesyan A, Dalisay DS, StelzerBraid S, Saunders N, Johnson J, et al. Analysis of the Pseudoalteromonas tunicata genome reveals properties of a surface-associated life style in the marine environment. PLOS ONE 2008; 3:e3252. PubMed http://dx.doi.org/10.1371/journal.pone.0003252

76. Cole JR, Wang Q, Cardenas E, Fish J, Chai B, Farris RJ, Kulam-Syed-Mohideen AS, McGarrell DM, Marsh T, Garrity GM, et al. The Ribosomal Database Project: improved alignments and new tools for rRNA analysis. Nucleic Acids Res 2009; 37:D141-D145. PubMed http://dx.doi.org/10.1093/nar/gkn879

77. Tamura K, Dudley J, Nei M, Kumar S. MEGA4: Molecular Evolutionary Genetics Analysis (MEGA) software version 4.0. Mol Biol Evol 2007; 24:1596-1599. PubMed http://dx.doi.org/10.1093/molbev/msm092

78. Field D, Garrity G, Gray T, Morrison N, Selengut J, Sterk P, Tatusova T, Thomson N, Allen MJ, Angiuoli SV, et al. The minimum information about a genome sequence (MIGS) specification. Nat Biotechnol 2008; 26:541-547. PubMed http://dx.doi.org/10.1038/nbt1360

79. DOE Joint Genome Institute. http://www.jgi.doe.gov

80. Ewing B, Green P. Base-calling of automated sequencer traces using phred. II. Error probabilities. Genome Res 1998; 8:186-194. PubMed

81. Ewing B, Hillier L, Wendl MC, Green P. Basecalling of automated sequencer traces using phred. I. Accuracy assessment. Genome Res 1998; 8:175-185. PubMed

82. Gordon D, Abajian C, Green P. Consed: a graphical tool for sequence finishing. Genome Res 1998; 8:195-202. PubMed
83. Han CS, Chain P. Finishing repeat regions automatically with Dupfinisher. In: Arabnia HR, Valafar $\mathrm{H}$, editors. Proceeding of the 2006 international conference on bioinformatics \& computational biology: CSREA Press; 2006. p 141-146.

84. Hyatt D, Chen GL, Locascio PF, Land ML, Larimer FW, Hauser LJ. Prodigal: prokaryotic gene recognition and translation initiation site identification. BMC Bioinformatics 2010; 11:119. PubMed http://dx.doi.org/10.1186/1471-2105-11-119

85. Pati A, Ivanova N, Mikhailova N, Ovchinikova G, Hooper SD, Lykidis A, Kyrpides NC. GenePRIMP: A Gene Prediction Improvement Pipeline for microbial genomes. Nat Methods 2010; 7:6. PubMed http://dx.doi.org/10.1038/nmeth.1457

86. Lowe TM, Eddy SR. tRNAscan-SE: a program for improved detection of transfer RNA genes in genomic sequence. Nucleic Acids Res 1997; 25:955-964. PubMed

87. Lagesen K, Hallin PF, Rødland E, Stærfeldt HH, Rognes T, Ussery DW. RNammer: consistent annotation of rRNA genes in genomic sequences. Nucleic Acids Res 2007; 35:3100-3108. PubMed http://dx.doi.org/10.1093/nar/gkm160

88. Griffiths-Jones S, Bateman A, Marshall M, Khanna A, Eddy SR. Rfam: an RNA family database. $\mathrm{Nu}$ cleic Acids Res 2003; 31:439-441. PubMed http://dx.doi.org/10.1093/nar/gkg006

89. Krogh A, Larsson B, von Heijne G, Sonnhammer ELL. Predicting transmembrane protein topology with a hidden Markov model: Application to complete genomes. J Mol Biol 2001; 305:567580. PubMed http://dx.doi.org/10.1006/jmbi.2000.4315

90. Dyrløv Bendtsen JD, Nielsen H, von Heijne G, Brunak S. Improved prediction of signal peptides: SignalP 3.0. J Mol Biol 2004; 340:783-795. PubMed http://dx.doi.org/10.1016/j.jmb.2004.05.028

91. Integrated Microbial Genomes (IMG) platform. http://img.jgi.doe.gov

92. Markowitz VM, Szeto E, Palaniappan K, Grechkin Y, Chu K, Chen IMA, Dubchak I, Anderson I, Lykidis A, Mavromatis K, et al. The Integrated Microbial Genomes (IMG) system in 2007: data content and analysis tool extensions. Nucleic Acids Res 2008; 36:D528-D533. PubMed http://dx.doi.org/10.1093/nar/gkm846

93. Möbus E, Maser E. Molecular cloning, overexpression, and characterization of steroidinducible 3alpha-hydroxysteroid dehydrogenase/carbonyl reductase from Comamonas 
testosteroni. A novel member of the short-chain dehydrogenase/reductase superfamily. J Biol Chem 1998; 273:30888-30896. PubMed http://dx.doi.org/10.1074/jbc.273.47.30888

94. Xiong G, Maser E. Regulation of the steroidinducible 3alpha-hydroxysteroid dehydrogenase/carbonyl reductase gene in Comamonas testosteroni. J Biol Chem 2001; 276:9961-9970. $\underline{\text { PubMed }}$

http://dx.doi.org/10.1074/jbc.M010962200

95. Pruneda-Paz JL, Linares M, Cabrera JE, GentiRaimondi S. TeiR, a LuxR-type transcription factor required for testosterone degradation in Comamonas testosteroni. J Bacteriol 2004;

186:1430-1437. PubMed http://dx.doi.org/10.1128/JB.186.5.1430$\underline{1437.2004}$

96. Birkenmaier A, Holert J, Erdbrink H, Moeller HM, Friemel A, Schoenenberger R, Suter MJ, Klebensberger J, Philipp B. Biochemical and genetic investigation of initial reactions in aerobic degradation of the bile acid cholate in Pseudomonas sp. strain Chol1. J Bacteriol 2007;

189:7165-7173. PubMed http://dx.doi.org/10.1128/JB.00665-07

97. Birkenmaier A, Möller HM, Philipp B. Identification of a thiolase gene essential for beta-oxidation of the acyl side chain of the steroid compound cholate in Pseudomonas sp. strain Chol1. FEMS Microbiol Lett 2011; 318:123-130. PubMed http://dx.doi.org/10.1111/j.15746968.2011.02250.x

98. Horinouchi $M$, Hayashi $T$, Koshino $H$, Malon $M$, Yamamoto T, Kudo T. Identification of genes involved in inversion of stereochemistry of a C-12 hydroxyl group in the catabolism of cholic acid by Comamonas testosteroni TA441. I Bacteriol 2008; 190:5545-5554. PubMed http://dx.doi.org/10.1128/JB.01080-07

99. Pérez-Pantoja D, Donoso R, Agullo L, Cordova M, Seeger M, Pieper DH, Gonzalez B. Genomic analysis of the potential for aromatic compounds biodegradation in Burkholderiales. Environ Microbiol 2012; 14:1091-1117. PubMed http://dx.doi.org/10.1111/j.14622920.2011.02613.x

100. Chang HK, Zylstra GJ. Examination and expansion of the substrate range of $m$-hydroxybenzoate hydroxylase. Biochem Biophys Res Commun 2008; 371:149-153. PubMed http://dx.doi.org/10.1016/j.bbrc.2008.04.032
101. Arai H, Ohishi T, Chang MY, Kudo T. Arrangement and regulation of the genes for metapathway enzymes required for degradation of phenol in Comamonas testosteroni TA441. Microbiology 2000; 146:1707-1715. PubMed

102. Arai H, Akahira S, Ohishi T, Maeda M, Kudo T. Adaptation of Comamonas testosteroni TA441 to utilize phenol: organization and regulation of the genes involved in phenol degradation. Microbio/ogy 1998; 144:2895-2903. PubMed http://dx.doi.org/10.1099/00221287-144-10-2895

103. Arai H, Yamamoto T, Ohishi T, Shimizu T, Nakata T, Kudo T. Genetic organization and characteristics of the 3-(3-hydroxyphenyl)propionic acid degradation pathway of Comamonas testosteroni TA441. Microbiology 1999; 145:2813-2820. $\underline{\text { PubMed }}$

104. Wang YZ, Zhou Y, Zylstra GJ. Molecular analysis of isophthalate and terephthalate degradation by Comamonas testosteroni YZW-D. Environ Health Perspect 1995; 103:9-12. PubMed

105. Chae JC, Zylstra GJ. 4-Chlorobenzoate uptake in Comamonas sp. strain DJ-12 is mediated by a tripartite ATP-independent periplasmic transporter. J Bacteriol 2006; 188:8407-8412. PubMed http://dx.doi.org/10.1128/JB.00880-06

106. Lévy-Schil S, Soubrier F, Crutz-Le Coq AM, Faucher D, Crouzet J, Petre D. Aliphatic nitrilase from a soil-isolated Comamonas testosteroni sp.: gene cloning and overexpression, purification and primary structure. Gene 1995; 161:15-20. PubMed http://dx.doi.org/10.1016/03781119(95)00242-X

107. Yang Y, Chen T, Ma P, Shang G, Dai Y, Yuan S. Cloning, expression and functional analysis of nicotinate dehydrogenase gene cluster from Comamonas testosteroni JA1 that can hydroxylate 3-cyanopyridine. Biodegradation 2010; 21:593602. PubMed http://dx.doi.org/10.1007/s10532010-9327-2

108. Yee LN, Chuah JA, Chong ML, Phang LY, Raha AR, Sudesh K, Hassan MA. Molecular characterisation of phaCAB from Comamonas sp. EB172 for functional expression in Escherichia coli JM109. Microbiol Res 2012; 167:550-557. PubMed http://dx.doi.org/10.1016/j.micres.2011.12.006

109. Jendrossek D, Backhaus M, Andermann M. Characterization of the extracellular poly(3hydroxybutyrate) depolymerase of Comamonas sp. and of its structural gene. Can J Microbiol 1995; 41(Suppl 1):160-169. PubMed http://dx.doi.org/10.1139/m95-183 